\title{
Dishabituation of the Tritonia Escape Swim
}

\author{
Donna L. Mongeluzi ${ }^{1}$ and William N. Frost ${ }^{2,3}$ \\ ${ }^{1}$ Department of Neurobiology and Anatomy \\ University of Texas Houston Medical School \\ Houston, Texas 77225 USA \\ ${ }^{2}$ Department of Cell Biology and Anatomy \\ The Chicago Medical School \\ North Chicago, Illinois 60064 USA
}

\begin{abstract}
When repeatedly elicited, the oscillatory escape swim of the marine mollusc Tritonia diomedea undergoes habituation of the number of cycles per swim. Although similar in most respects to habituation observed in vertebrates and other invertebrates, one key feature, dishabituation, has been surprisingly difficult to demonstrate. Here we evaluate the hypothesis that this is due to interference from short-term sensitization, which is manifested as a reduction in swim onset latency, that occurs simultaneously during habituation training. Robust dishabituation was obtained using a multisession habituation protocol designed to allow this sensitization to dissipate before the dishabituatory stimulus was applied. These results extend the similarity of habituation in Tritonia to that described in other species, strengthening the usefulness of this preparation as a model system for studies of the cellular basis of habituation.
\end{abstract}

\section{Introduction}

In the marine mollusc Tritonia diomedea, an aversive stimulus triggers a rhythmic escape swim consisting of a series of alternating ventral and dorsal whole-body flexions (Willows et al. 1973b). The neural circuitry underlying this response is well understood (Willows et al. 1973a; Getting 1983; Frost and Katz 1996), making this an attractive preparation for studying the neural basis of simple forms of learning and memory.

${ }^{3}$ Corresponding author.
When elicited repeatedly, this escape response undergoes habituation of a number of behavioral features, including the number of cycles per swim (Abraham and Willows 1971; Frost et al. 1996). A cardinal feature of habituation is dishabituationthe ability of a novel stimulus to partially or completely reverse the habituated response (Thompson and Spencer 1966; Hinde 1970). While habituation in Tritonia is quite similar to that described in other species (Frost et al. 1996), dishabituation has been difficult to demonstrate (Willows and Dorsett 1975; Frost et al. 1996).

It was reported previously that, in Tritonia, habituation training produces a simultaneous short-term sensitization, manifested by a reduction in swim onset latency (Brown et al. 1996). To evaluate the hypothesis that this co-sensitization may interfere with attempts to produce dishabituation, we first determined the duration of the sensitization. We then redesigned our training procedure so that dishabituation was attempted only after a sufficient rest period was introduced to allow recovery from sensitization. This procedure resulted in a robust dishabituation. While there are other possible explanations for past failures (see Discussion), this successful demonstration of dishabituation further establishes Tritonia as an attractive model system for studies of the cellular basis of habituation.

\section{Materials and Methods}

Animals were collected from the waters of Puget Sound, Washington, and maintained in natural running sea water aquaria $\left(11^{\circ} \mathrm{C}-13^{\circ} \mathrm{C}\right)$ at the University of Washington's Friday Harbor Laboratories. After arrival in the laboratory, all animals were rested for a minimum of 4 days. Before each experiment, animals were isolated and left undisturbed for a minimum of $3 \mathrm{hr}$. The training and

LEARNING \& MEMORY 7:43-47 @ 2000 by Cold Spring Harbor Laboratory Press ISSN1072-0502/00 \$5.00

$$
\begin{array}{lllllllllllllll}
L & E & A & R & N & I & N & G & \begin{array}{l}
\boldsymbol{Z} \\
\mathbf{4 3}
\end{array} & M & E & M & O & R & Y
\end{array}
$$


testing stimuli consisted of different concentrations and volumes of $\mathrm{NaCl}$ (with Fast Green added for visibility), applied with a 1-ml syringe over a period of 5-7 sec, as close as possible to the surface of either the head or the tail.

Animals were rejected from the experiment if their initial tail-elicited swim was $\leq 3$ cycles. To minimize their prior experience, animals were only eligible for experiments if they had been made to swim no more than three times while in captivity, and had rested a minimum of 4 days following any experimenter-induced swim. A total of 86 animals were used.

"Cycle number" refers to the number of complete cycles, each consisting of a ventral and dorsal flexion, per swim. "Swim onset latency" is defined as the number of seconds from stimulus onset to the maximum point of the first ventral flexion. Results are reported as mean \pm standard error. For experiments 1 and 3, univariate repeated measures analyses of variance (ANOVAs) were performed. For experiment 2, a univariate between-subjects ANOVA was conducted. Newman Keuls post hoc tests were performed following each univariate analysis. ANOVA analyses were conducted with the Statistica software package (Statsoft). All $P$ values are two-tailed.

\section{Results}

CO-OCCURRENCE OF HABITUATION

AND SENSITIZATION (EXPERIMENT 1)

Although repeated stimulation produces habituation of cycle number, it also simultaneously sensitizes swim onset latency (Brown et al. 1996). To evaluate whether this sensitization might be interfering with dishabituation, we first replicated the sensitization finding (Fig. 1).

Eight animals received ten consecutive swimeliciting salt stimuli $(0.15 \mathrm{ml}$ of $4 \mathrm{M} \mathrm{NaCl})$ delivered to the tail at a $2 \mathrm{~min}$ intertrial interval (Fig. 1A). The ANOVA revealed a significant effect of training on cycle number $[F(9,63)=29.48, P<0.001]$. Post hoc testing confirmed that significant cycle number habituation occurred over the course of training (first trial $=7.0 \pm 0.5$ cycles, tenth trial $=2.6 \pm$ 0.2 cycles, $P<0.001)$. As observed previously (Frost et al. 1996), the habituation curve resulting from this strong stimulus and short interstimulus interval decremented progressively, with no hint of any accompanying sensitization.

On the other hand, swim onset latency underwent a robust sensitization that co-occurred with the habituation (Fig. 1B). The ANOVA revealed a significant effect of training on latency $[F(9$, $63)=17.51, P<0.001]$. Post hoc tests indicated that swim onset latency shortened immediately after the first trial (first trial, $6.5 \pm 0.3 \mathrm{sec}$, second trial, $4.2 \pm 0.2 \mathrm{sec}, P<0.001)$ and was still significantly faster on the tenth trial $(5.6 \pm 0.3 \mathrm{sec}$, $P<0.001)$. Thus, repeatedly eliciting the Tritonia escape swim induces two simultaneous forms of nonassociative learning, habituation and sensitization.

THE DURATION OF LATENCY SENSITIZATION (EXPERIMENT 2)

Our next goal was to characterize the duration
A

Figure 1: Repeated stimulation produces both habituation and sensitization of the escape swim. (A) Ten consecutive salt stimuli applied to the tail produced a progressive habituation of the number of cycles per swim $[(*) P<0.001]$. (B) The same training produced an immediate sensitization of swim onset latency. Latency was shorter on the second trial and was still significantly shorter on the tenth trial $[(*) P<0.001]$.

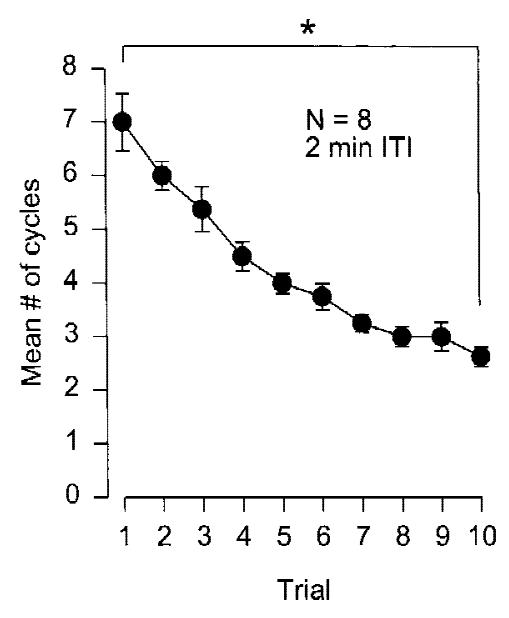

B

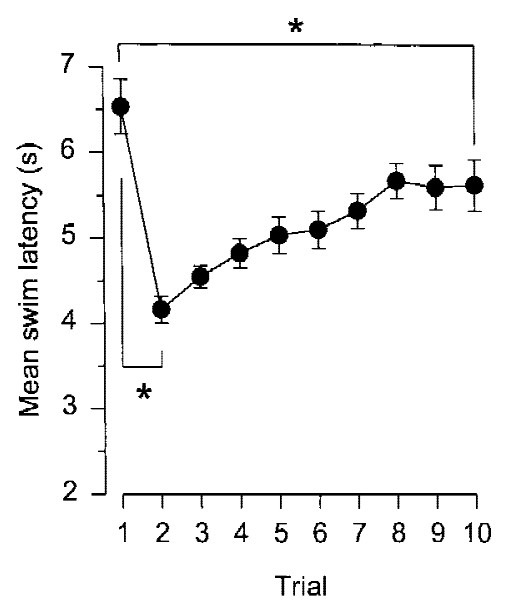

$$
\begin{array}{llllllllllllllll} 
& E & A & R & N & I & N & G & \begin{array}{l}
\boldsymbol{Z} \\
\mathbf{4} 4
\end{array} & M & E & M & O & R & Y
\end{array}
$$


of latency sensitization. In another study, using pairs of salt stimuli applied at different intervals to a single body site, we concluded that latency sensitization lasts between 1 and $2 \mathrm{hr}$ (Brown et al. 1996). To evaluate sensitization as completely isolated from habituation as possible, we used a twosite procedure in which the sensitizing stimulus was administered to a site different from the test stimulus.

Seventy animals were divided into 10 groups ( $n=7$ per group). One group received the test stimulus alone $(0.15 \mathrm{ml}$ of $4 \mathrm{M} \mathrm{NaCl})$, applied to the tail. The remaining nine groups received the same tail test stimulus at varying intervals $(2,4,8,15,30$, $60,120,180$, or $240 \mathrm{~min}$ ) after a sensitizing head stimulus $(0.3 \mathrm{ml}$ of $4 \mathrm{~m} \mathrm{NaCl})$. Swim onset latency to the single test stimulus was recorded for all animals in each group, and the results were plotted with respect to the time after the head stimulus. A one-way between-subjects ANOVA revealed an overall difference among the groups in their swim latency to the test stimulus $[F(9,60)=10.46$, $P<0.001]$. Post hoc tests revealed significant latency sensitization at all points from 2-60 min following the head stimulus, but not at later time points (Fig. 2). These results are consistent with Brown et al. (1996), and indicate that the shortterm sensitization produced by a single aversive stimulus is fully developed at $2 \mathrm{~min}$, and lasts $\geq 1$, but $<2 \mathrm{hr}$.

\section{DISHABITUATION (EXPERIMENT 3)}

The above findings support our hypothesis about why it has been so difficult to demonstrate dishabituation in Tritonia: In previous experimen- tal designs, animals were likely to have been in a sensitized state at the time of the dishabituation test, which could have blocked the expression of dishabituation. To test this idea we tried a new protocol, in which the dishabituatory stimulus was administered while habituation was still in effect, but after the animals were allowed to recover from short-term sensitization.

Eight animals received 7 habituation training sessions, with $4 \mathrm{hr}$ between the onset of each session (Fig. 3). Each session consisted of 10 tail stimuli $(0.15 \mathrm{ml}$ of $4 \mathrm{M} \mathrm{NaCl})$ delivered with a 2 min intertrial interval, leaving a $3 \mathrm{~h}$ and $42 \mathrm{~min}$ rest period from the last trial of each block to the first trial of the next. This is significantly longer than the $1 \mathrm{hr}$ of sensitization produced by a single swimeliciting stimulus.

During each 10-trial training block, the animals showed a decrementing cycle number response. They also showed progressive habituation across blocks, that is, the first trial of each block was lower than that of the previous block. A two-way repeated measures ANOVA revealed a significant within-session, $[F(9,63)=19.19, P<0.001]$, between-session $[F(6,42)=56.49, P<0.001]$, and within- $x$ between-session interaction $[F(54$, $378)=3.11, P<0.001]$. Post hoc testing revealed that the number of cycles declined significantly between the first trial of the first and sixth training sessions $(6.4 \pm 0.1$ vs. $1.1 \pm 0.1$ cycles, $P<0.001$; Fig. 3).

Five minutes before the start of the final (seventh) stimulus session, a single, stronger swim-eliciting stimulus was applied to the head (0.5-2.0 ml of $4 \mathrm{M} \mathrm{NaCl}$ ). Comparison of the first tail stimulus responses of the sixth and seventh training blocks

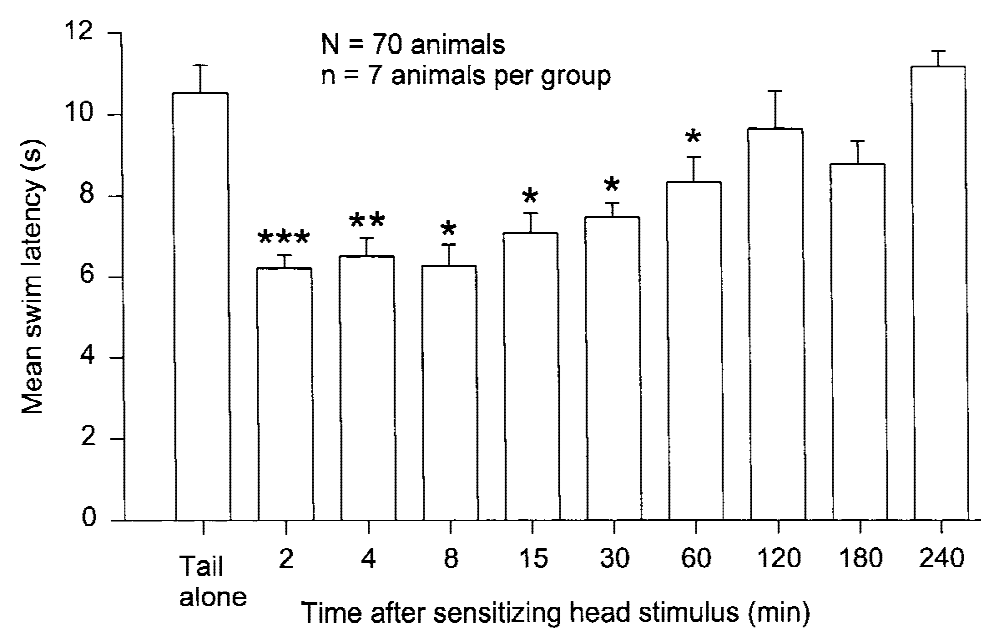

Figure 2: Duration of sensitization. Seventy animals were divided into 10 groups. One group received a single stimulus to the tail. Each of the other groups received a tail stimulus at the indicated interval following a sensitizing head stimulus. Sensitization was still present at $1 \mathrm{hr}$, but not at $2 \mathrm{hr}\left[\left({ }^{* * *}\right) P<0.001\right.$, (**) $P<0.01,(*) P<0.05]$.

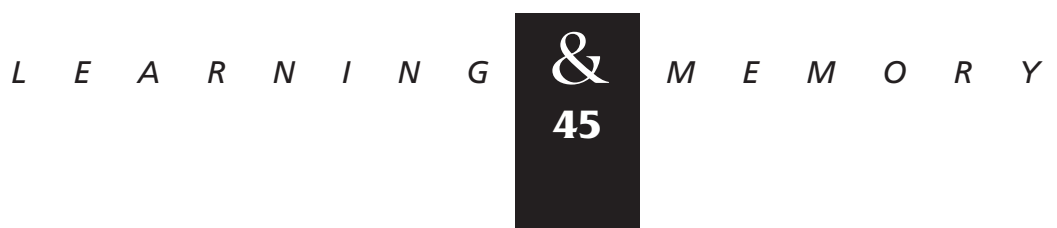


Figure 3: Dishabituation of swim cycle number. Eight animals were given seven sessions of habituation training, spaced at 4-hr intervals. Each session consisted of 10 salt stimuli applied to the tail with a 2-min intertrial interval. Five minutes before the start of the seventh session, all animals received a single dishabituatory salt stimulus to the head. Each point represents the mean cycle number for that trial $\left[\left(^{*}\right)\right.$

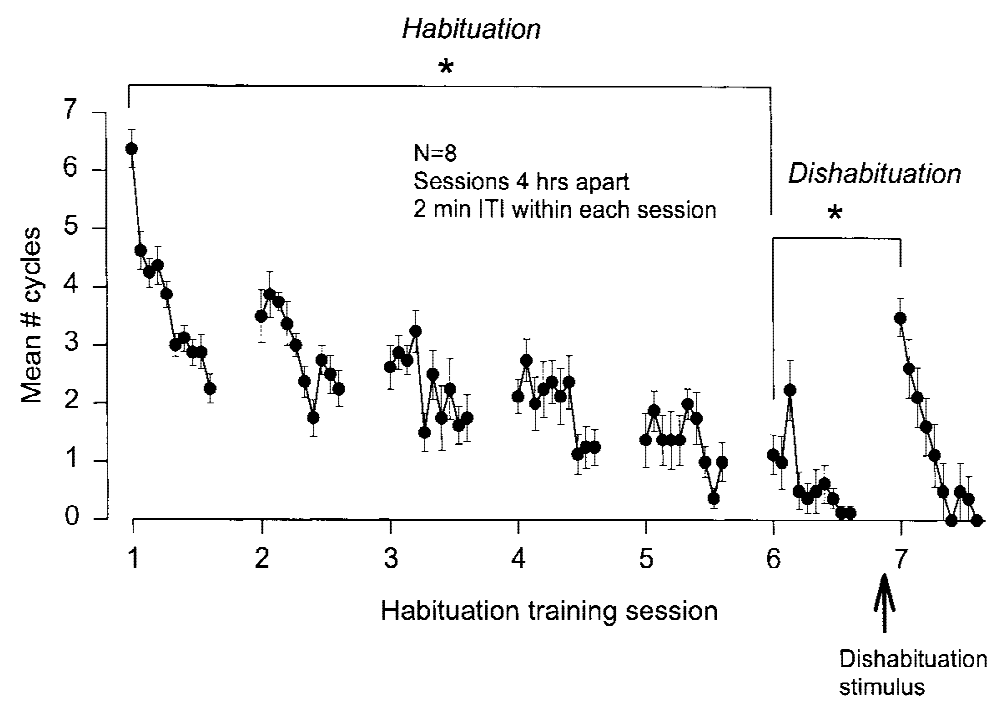

$(1.1 \pm 0.1$ cycles vs. $3.5 \pm 0.1$ cycles, respectively) revealed that the head stimulus produced significant dishabituation of the swim response $(P<0.001$; Fig. 3).

\section{Discussion}

Dishabituation has often been used to distinguish habituation, considered typically to be a central process, from simple effector fatigue. Effector fatigue has already been ruled out as playing a significant role in cycle number habituation in Tritonia, given the similar kinetics of habituation in the intact animal and the isolated brain preparation, where there is no effector apparatus (Frost et al. 1996). Nonetheless, we tested for dishabituation because it is viewed widely as one of the cardinal features of habituation (Thompson and Spencer 1966; Hinde 1970), and so its absence might have called into question the suitability of Tritonia as a model system for cellular studies of habituation.

Despite many attempts, previous efforts to demonstrate behavioral dishabituation in Tritonia have been largely unsuccessful (Willows and Dorsett 1975; Frost et al. 1996, but see Brown 1998). All of these protocols had one feature in common; that is, the dishabituatory stimulus was inserted into an ongoing, regularly-spaced series of habituation stimuli, with no significant rest period before the dishabituation attempt. Our present protocol made use of widely separated training blocks, to test for dishabituation while habituation was demonstrably present, but after other interfering effects of habituation training had had time to dissipate.
Our results are consistent with the hypothesis that prior efforts to produce dishabituation in Tritonia were frustrated by the presence of shortterm sensitization induced during habituation training. While this sensitization is frequently not evident in the cycle number curves, its presence is revealed by the reduced swim onset latency that occurs during habituation training. During habituation training, the very first stimulus produces sensitization of several behavioral features, including swim threshold, onset latency, and cycle number, as well as the latencies of the rhinophore and gill withdrawal reflex responses to the stimulus (Frost et al. 1998). Parallel examples occur in vertebrates, where for example, repeated acoustic stimulation produces habituation of the amplitude of the rat's startle response, together with a simultaneous sensitization of startle latency (Pilz and Schnitzler 1996). Such co-occurrence of decremental and incremental processes is the central feature of Groves and Thompson's influential dual process theory of habitation (Groves and Thompson 1970).

The simplest explanation for how sensitization might occlude dishabituation is that the two processes share common underlying mechanisms. While a common mechanism has been suggested for some time (Groves and Thompson 1970), several recent studies have concluded that dishabituation and sensitization are in some cases not mediated by identical processes (Rankin and Carew 1988; Erlich et al. 1992; Wright et al. 1992; Sahley et al. 1994).

An alternative to the sensitization interference hypothesis is that cycle number habituation may interfere with dishabituation by a decremental pro-

$$
\begin{array}{llllllllllllllll}
L & E & A & R & N & I & N & G & \begin{array}{l}
\boldsymbol{Z} \\
\mathbf{4 6}
\end{array} & M & E & M & O & R & Y
\end{array}
$$


cess. In this scenario, habituation training not only renders the circuitry less effective at eliciting swims, but also at invoking dishabituation. At present, our data do not allow us to distinguish decisively between these two possibilities. However, because we obtained dishabituation by introducing a rest period designed to produce recovery from sensitization but not habituation, the data appear presently to support more strongly the sensitization interference hypothesis.

Together with earlier works (Abraham and Willows 1971; Willows 1973; Willows and Dorsett 1975; Brown et al. 1996; Frost et al. 1996), this demonstration of dishabituation extends the similarity of habituation in Tritonia with examples described in other species. This similarity strengthens the suitability of Tritonia, with its large neurons and well understood swim circuitry, as a model system for studies of the cellular basis of habituation.

\section{Acknowledgments}

We thank Lise Eliot for comments on the manuscript and Friday Harbor Laboratories for use of their facilities. This research was supported by NIH Grants NS36500 and NS07373.

The publication costs of this article were defrayed in part by payment of page charges. This article must therefore be hereby marked "advertisement" in accordance with 18 USC section 1734 solely to indicate this fact.

\section{References}

Abraham, F.D. and A.O.D. Willows. 1971. Plasticity of a fixed action pattern in the sea slug Tritonia diomedia. Comm. Behav. Biol. 6: 271-280.

Brown, G.D. 1998. Nonassociative learning processes affecting swimming probability in the seaslug Tritonia diomedea: Habituation, sensitization and inhibition. Behav. Brain Res. 95: 151-165.

Brown, G.D., W.N. Frost, and P.A. Getting. 1996. Habituation and iterative enhancement of multiple components of the Tritonia swim response. Behav. Neurosci. 110: $478-485$.

Erlich, J.S., N.M. Boulis, T. Karrer, and C.L. Sahley. 1992. Differential effects of serotonin depletion on sensitization and dishabituation in the leech, Hirudo medicinalis. J. Neurobiol. 23: $270-279$.

Frost, W.N. and P.S. Katz. 1996. Single neuron control over a complex motor program. Proc. Natl. Acad. Sci. 93: 422-426.

Frost, W.N., G.D. Brown, and P.A. Getting. 1996. Parametric features of habituation of swim cycle number in the marine mollusc Tritonia diomedea. Neurobiol. Learn. Mem.

65: 125-134.
Frost, W.N., C.L. Brandon, and D.L. Mongeluzi. 1998. Sensitization of the Tritonia escape swim. Neurobiol. Learn. \& Mem. 69: 126-135.

Getting, P.A. 1983. Neural control of swimming in Tritonia. In Symposia of the Society for Experimental Biology (eds. A. Roberts and B. Roberts) pp. 89-128, No. 37, Neural origin of rhythmic movements. Cambridge University Press, London.

Groves, P.M. and R.F. Thompson. 1970. Habituation: A dual process theory. Psychol. Rev. 77: 419-450.

Hinde, R.A. 1970. Behavioral habituation. In Short term changes in neural activity and behavior (eds. G. Horn and R. A. Hinde), pp. 3-40. Cambridge University Press, London.

Pilz, P.K.D. and H.U. Schnitzler. 1996. Habituation and sensitization of the acoustic startle response in rats: Amplitude, threshold, and latency measures. Neurobiol. Learn. Mem. 66: 67-79.

Rankin, C.H. and T.J. Carew. 1988. Dishabituation and sensitization emerge as separate processes during development in Aplysia. J. Neurosci. 8: 197-211.

Sahley, C.L., B.K. Modney, N.M. Boulis, and K.J. Muller. 1994. The $S$ cell: An interneuron essential for sensitization and full dishabituation of leech shortening. J. Neurosci. 14: 6715-6721.

Thompson, R.F. and W.A. Spencer. 1966. Habituation: A model phenomenon for the study of neuronal substrates of behavior. Psychol. Rev. 73: 16-43.

Willows, A.O.D. 1973. Learning in gastropod mollusks. In Invertebrate learning. Vol. 2: Arthropods and gastropod mollusks (ed. W.C. Corning, J.A. Dyal, A.O.D. Willows), pp. 187-274.

Willows, A.O.D. and D.A. Dorsett. 1975. Evolution of swimming behavior in Tritonia and its neurophysiological correlates. J. Comp. Physiol. 100: 117-133.

Willows, A.O.D., D.A. Dorsett, and G. Hoyle. 1973a. The neuronal basis of behavior in Tritonia. I. Functional organization of the central nervous system. J. Neurobiol. 4: 207-237.

1973b. The neuronal basis of behavior in Tritonia. III. Neuronal mechanism of a fixed action pattern. J. Neurobiol. 4: 255-285.

Wright, W.G., E.F. McCance, T. Lu, and T.J. Carew. 1992. Delayed-onset sensitization emerges after dishabituation in developing Aplysia. Behav. Neural Biol. 57: 170-174.

Received September 8, 1999; accepted in revised form November 10, 1999.

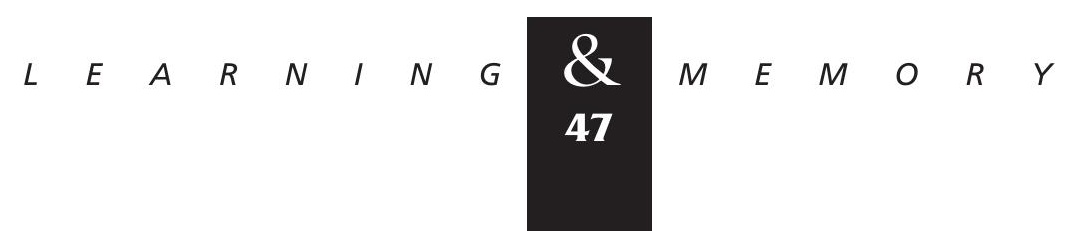




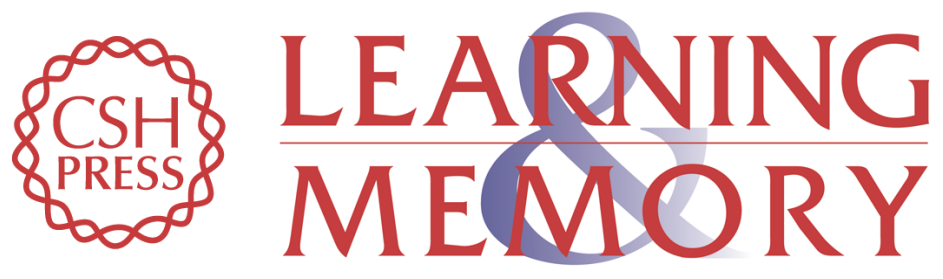

\section{Dishabituation of the Tritonia Escape Swim}

Donna L. Mongeluzi and William N. Frost

Learn. Mem. 2000, 7:

Access the most recent version at doi:10.1101//m.7.1.43

References This article cites 15 articles, 3 of which can be accessed free at: http://learnmem.cshlp.org/content/7/1/43.full.html\#ref-list-1

License

Email Alerting Receive free email alerts when new articles cite this article - sign up in the box at the Service top right corner of the article or click here. 